\title{
O CURRÍCULO
}

Dáugima Maria dos Santos Queiróz*

Ieda Marques de Carvalho**

Maineide Zanoto Velasques***

\section{1 - INTRODUÇÃO}

Inúmeras são as questões suscitadas pela reflexão em torno dos problemas da educação, variando desde as indagações sobre sua tecnologia, funções e até mesmo os seus objetivos e finalidades últimas, cujas implicações refletem-se na postura e no trabalho dos trabalhadores.

* Graduada em Pedagogia pela FUCMT, pós-graduada (lato-sensu) em Didática do Ensino Superior, professora de Didática e Prática de Ensino na UCDB e cursa o Programa de Mestrado em Educação na UCDB.

** Licenciada em Pedagogia pela FUCMT, pós-graduada (lato-sensu) em Didática e Metodologia do Ensino Superior e em Didática para Educação de Adultos. Professora na UCDB, onde também é chefe da Assessoria de Planejamento e Desenvolvimento Institucional. Cursa o Programa de Mestrado em Educação na UCDB.

*** Professora de Botânica do Curso de Biologia da UCDB. Cursa o Programa de Mestrado em Educação na UCDB. 
O questionamento vem perspassando os momentos históricos da humanidade em sua busca ininterrupta de conhecer e conhecer-se, para compreender o mundo e viver melhor.

Nas três últimas décadas, estas questões assumiram proporções tais, que tornam praticamente impossível qualquer enfoque sobre a Educação ou quaisquer dos seus aspectos, sem que haja uma abordagem prévia em torno de conceitos e premissas, nas quais eles se baseian.

A Educação pode ser observada sob a ampla visão de que ela consiste em formar e socializar o indivíduo, bem como sob a ótica específica do contexto escolar. Contudo, como o afirma Forquim:

"É necessário reconhecer que, se toda educação é sempre educação de alguém por alguém, ela supõe sempre também, necessariamente, a comunicação, a transmissão, a aquisição de alguma coisa: conhecimento, competência, crenças, hábitos, valores, que constituem o que se chama precisamente de "conteúdo"da educação." (1993:10).

Este conteúdo provém da representação simbólica da natureza no mundo da cultura e se expressa através da linguagem. É o conteúdo que dá forma e consistência à experiência individual, sendo sempre algo que a precede, ultrapassa e delineia os contornos do ser humano enquanto tal. Por outro lado, sendo sempre a "educação de alguém por alguém", ela implica em controle social com uma abrangência que analisa, de forma mais acurada, ul- 
trapassa a área da sociologia educacional. É inegável que as influências dos setores econômicos, políticos e outros, perpassam, ideologicamente, a educação e são fatores determinantes dos currículos escolares.

$\mathrm{O}$ currículo tem responsabilidade de transmitir e perpetuar a experiência humana, filtrando aquilo que, ao longo dos tempos, vem sendo considerado saber cumulativo, controlável e básico para toda a vida intelectual, científica e artística, numa visão hegemônica da classe dominante. Contudo outros olhares sobre o currículo enxergam-no com funções que transcedem as retro mencionadas, podendo contribuir para tornar a humanidade menos estratificada e mais contente consigo própria.

Internacionalmente, a pluralidade de orientações teórico-metodológicas tem provocado debates científicos contraditórios. No Brasil, a reflexão sobre currículo tem sido a temática de inúmeros encontros e simpósios educacionais. Teorias de autores estrangeiros são evidenciadas e há tentativas de ajustes e aplicações à realidade nacional.

O professor Antonio Flávio B. Moreira, participando da $9^{\mathrm{a}}$ Conferência da Educação, discorreu sobre o tema: "Escola, currículo e construção do conhecimento", tendo como referencial a proposta de Michael Young, precursor da Nova Sociologia da Educação e de quem foi discípulo.

Nessa ocasião, manifestando-se sobre a produção do conhecimento na escola brasileira contemporânea, Moreira faz diversos questionamentos e aponta alguns 
aspectos que podem favorecer a reflexão em torno das questões levantadas. Entre elas, ressalta-se: "Que princípios devem nortear os esforços para selecionar, organizar e tratar conteúdos a partir de uma perpectiva criti$c a$ ?" (1991:81); e será esta a grande questão que se procurará responder neste trabalho, com base ao paradigma de Michael Young.

$\mathrm{Na}$ sua seqüência pretende-se apresentar a visão histórica de currículo no Brasil e a "nova sociologia da educação" de Young, como referenciais teóricos, considerando a coexistência de razões pedagógicas e sociológicas nos princípios didáticos de um currículo, que se ousa pretender como crítico, dinâmico e passível de ser construído na prática cotidiana dos educadores e educandos.

\section{O CURRÍCULO}

\subsection{Considerações Preliminares}

Preliminarmente, há que se apresentar o conceito de currículo. Visto sob o enfoque tradicional, o currículo se constitui na organização de conteúdos e representa um firme compromisso com a racionalidade histórica, sendo politicamente conservador. Uma nova visão de currículo, mostra-o como metodologia ou processo didático, no qual interagem todos os fatores educacionais e as respectivas 
relações e inter-relações que ocorrem no âmbito escolar, historicamente contextualizado, promovendo a transformação escolar.

$\mathrm{O}$ primeiro procura manter o estudante passivo e incapaz de perceber os percursos ideológicos que exibem seu raciocínio. A própria organização e compartimentalização das disciplinas leva-o a inferir que o mundo está assim organizado e não pode e nem deve sofrer alterações.

A segunda modalidade de currículo, na concepção de Giroux, objetiva desenvolver formas de entendimento que relacionem explicações de significados sociais, ampliando parâmetros societários e julgando suas exigências para a verdade. Ou, como reflete Young, este tipo de currículo concebe a educação como uma atividade prática, na qual a interação professor-aluno possibilita a atribuição de significados ao mundo e à própria vida; o conhecimento é visto como resultado das tentativas, feitas pelo homem, de organizar as relações recíprocas e as que ele mantém com a natureza, no decorrer da história. Este entendimento tem como conseqüência a compreensão de que a seleção curricular convencional é arbitrária e direcionada, provocando, cada vez mais, o seccionamento das disciplinas; exige que professores e alunos se vejam responsáveis pelo que sabem, constroem e criam, trabalhando juntos.

É sob esta perspectiva que Nova Sociologia de Educação busca analisar e discutir os problemas relativos à transmissão dos conhecimentos e ao desenvolvimento sócio-cultural do aluno; o que também enseja o 
direcionamento deste trabalho, ao tratar dos princípios didáticos a serem considerados na prática pedagógica.

\subsection{A educação e o currículo}

No decorrer da história, o homem vem refinando suas formas de controle sobre a natureza e sobre os outros homens. Nos primórdios da era industrial, houve um momento em que a relação de escravismo perdeu sua importância. Passou-se a buscar formas mais sutis de dominação social, com razões ideológicas subjacentes, sobre as quais não se tem interesse em delongar.

A área do currículo está enraizada no terreno do controle social. Emergiu como paradigma intelectual, no início deste século, como conjunto estabelecido de procedimentos para seleção e organização do conhecimento escolar, a ser transmitido aos professores. Por seu intermédio, pretendia-se resguardar interesses que extrapolavam a área da sociologia educacional, predominantemente, os da área econômica e política. Franklin Bobbitt e W.W. Charters foram os primeiros a se denominarem especialistas em currículo e estavam bastante impregnados das idéias de que o progresso depende de um trabalho de eugenia, do controle de quantificação social e da administração científica dos países. Tinham, portanto, como tarefa estabelecer critérios para selecionar os conhecimentos e significados que deveriam ser passados aos 
alunos na escola, com vistas à concretização das idéias por eles preconizadas.

Vale enfatizar que não se pretende evidenciar que o controle social é sempre indesejável. A organização em sociedade requer, no mínimo, um certo controle para a preservação de formas de interação social. O que se questiona é a sua determinação sobre os grupos. Entende-se que as regras comuns devem ser estabelecidas, vivenciadas e modificadas no cotidiano da sociedade.

O professor Bruno M. Bellerate, abordando o tema Ideologia e Didática, esquematiza interessante histórico que oferecé uma síntese da evolução da Didática e da Ideologia, partindo da comparação entre duplas de situações ocorridas em momentos diferentes. Sua primeira dupla enseja visualizar o panorama dos primórdios da educação brasileira e seu currículo norteador.

Primeiramente, Bellerate estabelece relações entre os jesuítas e Comenius cujas teorias apresentam analogias e dicotomizações. Tanto os jesuítas, em sua Ratio Studium, quanto Comenius, em sua Didáctica Magna, valorizaram a memória, os meios para reforçá-la e a organização sistemática dos estudos e metodologias; tiveram a mesma inspiração religiosa regulando a atividade educativa com vistas à Revelação, configurada como elemento transcendente à própria existência humana. Contudo os jesuítas voltaram seu trabalho para favorecer as classes elevadas, o que justifica a severidade, o incentivo às disputas e a preferência pelo ensino superior e pelo uso do latim como língua básica fundamental para os estudos. Para Comenius, o importante é "ensinar tudo a todos" 
sem restrições, o que o leva a interessar-se pelo ensino primário, utilizar-se do trabalho grupal (ensino mútuo) e valorizar o estudo da língua materna.

Como explicar estas diferenças, se ambas as correntes educativas têm a Bíblia como fonte inspiradora? Bellerate afirma que, justamente, por originarem em uma fonte ideológica, sua interpretação teve conotações diferentes. Os jesuítas centraram-se na autoridade e na conservação da situação vigente, porque esta seria a vontade de Deus. Comenius partiu da convicção de que todo homem faz parte da mesma realidade divina e, por isto, ele exortava a atividade de todos e de cada um, que tem, igualmente, os mesmos direitos e deveres. Comenius não foi um reducionista, pelo contrário, foi mais coerente e global na avaliação e aplicação da ideologia preconizada.

Tanto a nível nacional quanto internacional, os jesuítas, pela organização e difusão dos trabalhos, tiveram maior influência que Comenius. Seus pressupostos embasaram, por séculos, a organização currícular do seletivo e restrito sistema escolar brasileiro.

O método Pestalozzi, utilizando subsídios didáticos tradicionais, revestidos com uma roupagem sócio-filosófica e a escola nova de J.Dewey, com método e meios organizados, visando à funcionalidade e a promoção pessoal, sem incidência direta sobre a vida social, cinzelaram momentos do currículo e da educação nacional, anteriores às últimas décadas, que passam a merecer maior destaque, dada a proximidade com o momento atual. 
Guiomar Namo de Melo, no seminário "Gestão Escolar: desafios e tendências", realizado em Brasília, julho de 1993, traçou o panorama da eficácia escolar que, entendida como qualidade de ensino, coloca em evidência questões de organização institucional e pedagógica da escola. Os anos 60 e 70 foram marcados pela descrença da importância política e econômica da educação. Na Europa, Bourdieu e Passeron, com suas teorias críticoreprodutivistas, denunciavam que a vida na escola não tinha qualquer repercussão no destino das classes sociais. Nos Estados Unidos, Colemam e Jenks anunciavam que a determinação do sucesso escolar condiciona-se a condições externas à escola. As pesquisas pautaram-se na abordagem skinneriana e consideraram apenas os elementos passíveis de tratamento experimental, como objeto de investigação. Assim é que as relações escolares internas e a dinâmica do processo ensino-aprendizagem deixaram de fazer parte do campo de pesquisa. E o resultado foi um pessimismo generalizado. A continuidade das investigações contribuiu para desmistificar o pedagogismo ingênuo e estabelecer o conflito entre teorias reprodutivistas e crítico-reprodutivistas.

No Brasil, Saviani, Libâneo e a própria Guiomar Mello, entre outros, procuraram defender a importância da organização interna da escola para o desempenho dos alunos e da escolariedade para ensejar alternativas de vida das camadas sociais menos favorecidas. Neste sentido, a pesquisa educacional, nos anos 70 e 80 , contribuíram para tornar mais nítida a relação entre escola e sociedade no Brasil. Porém não houve avanço significativo em relação à produção de conhecimentos para ensejar políticas de 
melhoria qualitativa, que incidissem sobre as formas de organização escolar e as práticas da sala de aula.

Os fatos apontados nortearam, até agora, a elaboração dos currículos e os princípios didáticos que vem sendo propostos para a escola brasileira.

\subsection{Perspectivas para uma nova sociologia da educação}

Para Michael F.D. Young é necessário entender as instituições de ensino, como locais de material humano e como lugares de gestão e de organização do material cognitivo e simbólico. Em seu texto de introdução em Knowledge and Control, Young sugere que a sociologia da educação caminhe pari passu com a sociologia do conhecimento. Ambas devem ser aplicadas às interações na sala de aula, às categorias mentais dos professores e aos saberes escolares. Estes últimos são produtos sociais e a questão do saber está, intimamente, relacionada a do poder de controle social.

Os pressupostos ideológicos e os interesses dos grupos sociais dominantes embasam os processos de seleção e de organização dos conteúdos cognitivos e culturais do ensino. Em conseqüência, há três critérios possíveis para uma classificação dos currículos: segundo o grau de hierarquização, o de especialização, o de compartimentalização dos saberes que os currículos contribuem para transmitir. A questão mais importante para Young é a da hierarquização dos conteúdos ensinados, pois é ela que enseja a compreensão dos fatores políticos da trans- 
missão do saber, no interior dos sistemas de ensino. Quanto maior a estratificação, mais hierarquizadas são as relações entre professores e alunos. Os demais critérios evidenciam que quaisquer alterações nos currículos encontram fortes resistências, por colocarem em jogo interesses sociais e interesses simbólicos.

A rígida estatização do conhecimento, no âmago dos sistemas escolares, facilita a avaliação formal, fortalece o sistema de controle e confere prestígio às escolas que privilegiam estas ações, resultando em maior concorrência às vagas oferecidas e melhores sálarios aos seus docentes. Em última instância, descarta a possibilidade de surgir um currículo alternativo.

A estratificação do saber coloca a escola como importante agente de reprodução cultural e econômica, assegurando a manutenção de um poder desigual na sociedade, o que, em verdade, é resultado da estrutura do currículo e não da natureza dos saberes nele incorporados. $\mathrm{Na}$ estrutura do currículo, o conhecimento é recontextualizado, de acordo com o novo campo onde está inserido. O conceito original, pertinente a outros campos, descaracteriza-se. Há necessidade de aprofundar e ampliar pesquisas para entender a dinamização do conjunto de regras, proveniente do campo pedagógico, através do qual conhecimentos distintos se transformam em conhecimento escolar.

Young sugere que as matérias escolares sejam constituídas de "conjunto de significações comumente partilhadas", ou seja, que tenham caráter de construção social e que a avaliação escolar seja resultado de um processo, 
onde não sejam evidenciados o absolutismo do professor e nem a ignorância dos alunos, pelo contrário, há que existir uma negociação social. Por aí perpassa a idéia de que o critério máximo da avaliação é o progresso humano e a questão do conhecimento é, essencialmente, uma questão política.

Por mais pertinentes que sejam, as reflexões de Young estão a exigir aplicação prática para que se amplie sua sistematização conceitual e tenha concreta sustentação empírica.

\subsection{Princípios didáticos}

A nova sociologia da educação de Young deixa claro que a questão da escola é uma questão política e que, por mais que seja dominada pelos interesses das classes privilegiadas, é no seu interior que podem ser travadas importantes batalhas na luta pela transformação social, almejada pelos menos favorecidos da sociedade. Grande parte dos professores brasileiros vêm demonstrando angústia e ansiedade em relação à situação educacional do país. Há necessidade de superar-se o momento da crítica e, a partir dela mesma, elaborar propostas que resultem em alternativas e soluções. Não basta a análise situacional do contexto maior, desvinculada da prática e do próprio interior da escola.

A prática pedagógica que tenha vínculos com os referencias didáticos e sociológicos abordados, generali- 
zando processos e procedimentos resultantes da investigação das ciências que embasam o ensino e das situações que ocorrem na dinâmica interna da sala de aula, deve estar sustentada pelos seguintes príncipios:

1) Reflexão sobre o contexto sócio-cultural, escolar e condições iniciais do aluno;

2) Compreensão dos objetivos de educação e do progresso do ensino em seus múltiplos aspectos;

3) Formação continuada do professor;

4) Redimensionamento da prática pedagógica e da organização institucional e social da escola;

5) Análise do processo avaliativo.

Estes princípios estão sendo vistos como conjunto, dinamicamente, relacionado. Sua apresentação como momentos sucessivos num processo é apenas para uma melhor compreensão do que se pretende detalhar, no intuito de esclarecer as razões pelas quais foram escolhidos e contribuem para sua aceitação no seio da sociedade educacional. Sabe-se que apontar princípios didáticos a serem considerados na prática pedagógica e evidenciálos como conjunto dinâmico, conforme se ousa pretender, não é uma tarefa fácil, o que explica as precauções didáticas que foram tomadas. 


\subsubsection{Reflexão sobre o contexto sócio-cultural, escolar e condições iniciais dos Alunos}

Esta reflexão leva à compreensão do mundo atual, que se expressa pela descrição e julgamento dos seus aspectos social, econômico, político, cultural, religioso e educacional. As indagações sobre como se apresenta o contexto em que se está inserido, ressalta alguns aspectos em detrimento de outros, o que significa um julgamento do qual resulta uma tomada de posição sobre o que é adequado e coerente com os objetivos pretendidos e os instrumentos disponíveis para alcançá-los. Este posicionamento é delineado pelo fator ideológico, que pode resultar na ocultação da realidade, exigindo atenção e cuidados especiais, para que isto não ocorra.

Somente a reflexão, envolvendo toda a equipe educacional, possibilita entender as razões e intenções que orientam os objetivos educacionais, não resultando apenas na aceitação de uma postura ou doutrinas, mas determinando a construção social da realidade e os seus contornos, sem detrimento do patrimônio cultural, já amealhado pela humanidade.

A escola vem-se utilizando de meios "aparentemente terapêuticos" para eliminar a diversidade e manter a homogeneidade do fluxo intelectual, ignorado a importância da surpresa e do conflito, que são, essencialmente, criativos e geram mudanças, caracterizando, de maneira singular, os vários grupos sociais. No recôndito da sala de aula é que se concretizam o poder e a arbitrariedade. 
A obediência e a ordem são impostas aos alunos e não construídas, coletivamente.

A construção coletiva se faz pela aceitação das experiências já vivenciadas e das motivações que o aluno traz à sala de aula, cujo aproveitamento resulta na reelaboração de significado e valores inerentes àquele grupo. Faz-se, também, pela reflexão crítica do que é ensinado ou é mediado pela cultura escolar ou torna-se significativo pelo estudo, e pela ação conjunta de educadores que, incorporando os novos significados, edificam outra realidade e o seu próprio progresso, deles resultando a emancipação, preconizada nos objetivos últimos da educação.

2.4.2 Compreensão dos objetivos da educação e do progresso do ensino em seus mútlipos aspectos

A posição central que ocupa a escola, na rede de distribuição de informações de outras instituições (como as de saúde, economia, política, cultura), não permite que a mesma evidencie a posição de neutralidade ideológica que the vem sendo conferida, conforme vem enfatizando a professora Pura Lúcia O. Martins.

Sendo a escola distribuidora de valores e conhecimentos, a elaboração dos objetivos da educação deve permitir e promover questionamentos sobre as relações do poder e controle social para que, na seleção de conteúdos, o currículo favoreça a emancipação do indivíduo, 
não o seu subjugo, nem a reprodução de crenças culturais e relações econômicas que mantêm a ordem social, como ela se apresenta hoje. É inevitável o estabelecimento de uma ordem social, mas o que se pretende com a elucidação dos objetivos da educação é que eles promovam uma ordem cujo acesso às condições de ser e viver feliz sejam acessíveis a todos.

Compreender a educação, como processo complexo e dinâmico, implica na elaboração de objetivos norteadores da prática pedagógica, com uma visão crítica do seu papel no cotidiano da escola. Estes serão perseguidos, de forma clara e consentida pela comunidade que os traçou e que não medirá esforços para alcançá-los, conscientemente. Nessa fase é indispensável que se compreenda o papel de escola num contexto bem mais amplo, ou seja, naquele já mencionado, onde a escola está inserida. Levar em conta as influências culturais, sociais e econômicas dos alunos é fundamental para uma prática pedagógica eficiente. Essa análise possibilita definir a função do grau de ensino em que se atua e conhecer suas especificidades, delineando objetivos condizentes com a realidade das escolas públicas e das classes populares que as freqüentam.

As discussões acerca da definição dos objetivos norteiam o caminho, mas não indicam, obrigatoriamente, os passos a serem dados nesse processo. Permitem fazer contínua reavaliação crítica do processo educativo diário, desenvolvido nas salas de aula, que gera diferentes significados, valores culturais, relações e controles sociais. Estes significados não devem ser ignorados pelos curriculistas, pois eles é que vão influenciar o desenvol- 
vimento do pensamento crítico e a ação de cada um sobre suas histórias de vida.

Assim as questões que, na forma tradicional de se conceber os fins da educação, eram ignoradas, como as relações entre ideologia, controle social e conhecimento escolar, passam a ser fundamentais e significativas.

Visto sob esta ótica, o plano curricular deve explicitar, metodologicamente, o que se pretende, numa linguagem que apresente, com clareza, o como buscar a criatividade. Sua implementação corresponde a meios de julgamento sobre a natureza do conhecimento, das relações sociais de sala de aula e a distribuição do poder. Ao se promover a reflexão crítica e a compreensão humana, tem-se mais próxima a definição de verdade e o significado para o modelo de currículo e prática pedagógica.

É por esta razão que os princípios que regem a educação devem ser desafiadores das formas existentes de opressão institucional, que trazem consigo o peso das normas e interesses específicos "ignorar esta noção é abandonar a possibilidade para alunos e professores do mesmo modo de moldar a realidade em uma imagem outra que é socialmente prescrita e legitimada institucionalmente." (Giroux. 1981:194).

Ainda Giroux, abordando a nova sociologia do currículo, diz que "a teoria curricular crítica deve ser situacional', assim também devem ser os princípios educacionais, permeando as várias dimensões da educação como partes da sua conjuntura cultural e histórica. É usar os conceitos de sociologia e política, por exemplo, para 
enriquecer e ampliar o enfoque dado aos objetivos em uma determinada realidade educacional.

Concorda-se com Girox, quando este afirma que o progresso do ensino deve deixar espaço para a individualidade dos grupos, para a originalidade e necessidade pessoal da realidade específica, vinculadas à necessidade social do grupo maior.

Em síntese, os objetivos da educação e o progresso do ensino em seus múltiplos aspectos precisam deixar claro as relações que ocorrem entre os diferentes grupos culturais, contribuindo para emancipar as classes populares das imposições a que são submetidas num padrão de currículo tradicional.

\subsubsection{Formação continuada do professor}

A importância e o significado do papel do professor não dependem dele, seu valor lhe é atribuído pela sociedade que o produz e que compreeende a escola como uma instituição social.

A sociedade contemporânea atribuiu ao professor o papel de sacerdote, colocando sua tarefa a nível de missão, semelhante ao trabalho dos religiosos. Esta "sublimação" profissional do professor foi um produto social que influenciou seu modo de ser e de agir. Posteriormente, o professor passou a ser visto como profissional liberal, privilegiando-se o seu saber específico e incluindo- 
se, desta maneira, o trabalho intelectual no processo de produção do mundo capitalista, que compra aquilo que Ihe interessa.

A formação do profissional do magistério deve levá-lo a compreeender que não é mero produto a ser comercializado, necessitando rever o seu papel e o lugar que ocupa na realidade que o rodeia, numa perspectiva histórica e, socialmente, contextualizada. Esta formação irá refletir-se sobre o seu desempenho, pressupondo uma relação forte entre o saber e o saber-fazer-pedagógico, intrinsecamente relacionados às condições e experiências de vida do professor.

Segundo Mello:

"É preciso capacitar a escola e os professores para desempenharem com sucesso a tarefa de ensino-aprendizagem. Nenhuma medida política educacional, nem decreto ou norma poderá reverter a expectativa negativa da escola e dos professores diante de alunos de origem desfavorecida enquanto não se formar uma competência técnica que leve ao sucesso e prove, aos que não sabem ensinar, que as crianças são ensináveis, desde que o trabalho didático-pedagógico seja feito com adequação às suas características $e$ necessidades." (1993:16).

Isto implica no surgimento de uma nova concepção de relação existente entre o sujeito e o conhecimento. Significa entender que aprender não é estar em atitude 
contemplativa, frente aos dados culturais da sociedade e, sim, estar ativamente envolvido na produção e interpretação destes dados e na localização dos sujeitos, numa perspectiva de constante indagação.

A pesquisa, nesta visão, passa a ter um sentido especial, pois envolve o professor na tarefa de investigar e analisar o seu próprio mundo, como o enfatiza a professora Marli André, ao afirmar.

"O estudo do cotidiano escolar se coloca como fundamental para se compreender como a escola desempenha o seu papel socializador, seja na transformação dos conteúdos acadêmicos, seja na veiculação das crenças e valores que aparecem nas ações, interações, nas rotinas e nas relações sociais que caracterizam o cotidiano da experiência escolar." (1989:39).

Esta concepção exige que a pesquisa deixe de ser um mito para ser uma prática acessível, em suas proporções, a todos os professores e a todos os alunos. Ela deve ser usada para colocar o sujeito diante dos fatos, para que a realidade seja apreendida e não somente reproduzida. Sem um referencial básico de apoio, a pesquisa pode cair num empirismo vazio e, conseqüentemente, não contribuir para um avanço em relação ao que já é conhecido.

O professor precisa ensinar pesquisando e pesquisar ensinando, o que exige que ele receba por parte da escola uma assessoria técnico-pedagógica que o auxilie a 
desenvolver, com competência e segurança, o seu trabaho junto com os seus alunos.

A troca de experiências com outros docentes, não só entre os profissionais da sua escola, mas entre aqueles que compõem sua entidade de classe, enseja ao professor analisar e refletir sobre a sua própria condição e prática pedagógica, possibilitando que ele se veja como um trabalhador inserido no sistema de produção, o que é fundamental para uma ação transformadora de sua realidade e da que o rodeia.

2.4.4 Redimensionamento da prática pedagógica, organização institucional e social da escola

A preocupação dos educadores brasileiros com a escola pública e sua importância para as classes populares tem aumentado muito nos últimos anos, considerando o enorme contingente de crianças e adolescentes, originários das camadas sociais mais baixas, que chegam à escola e não são atendidos em suas expectativas mais elementares.

Sob o discurso de que, primeiramente, seria necessário resolver-se o problema da quantidade (escola para todos), deixou-se o atendimento à qualidade para depois, quando o país atingisse melhores condições gerais. E a qualidade do ensino foi-se deteriorando, gradativamente, sem que os problemas de quantidade fossem resolvidos. 
Pesquisa realizada pela professora Guiomar Mello, levou-a a afirmar:

"Pude constatar que a escola do pobre, mais que uma instituição inculcadora de ideologia, é o reino da ignorância, do descaso, da descontinuidade, da ausência do controle. É um terreno de ninguém, naquilo que é substancial, e um mundo rigidamente normatizado naquilo que é indispensável." (1983:15).

É uma necessidade urgente resgatar a importância da escolaridade para as estratégias de vida das camadas sociais desfavorecidas, enfocando a atenção para a organização interna da escola, como determinante imprescindível para o desempenho dos alunos.

Os estudos de Purkey \& Smith (1983) apontam um núcleo básico de características das escolas eficazes. A análise de algumas delas associadas a outras reflexões compõem o panorama que se idealiza para melhor redimensionamento da prática pedagógica e da organização institucional e social da escola.

As escolas apontadas como eficazes possuem, à frente dos trabalhos administrativos e pedagógicos, um elemento que exerce forte liderança, ou seja, conduz as atividades da escola como objetivos determinados com competência, dando segurança a toda equipe escolar. Na maioria dos casos, esta liderança não é encontrada nas escolas consideradas de baixo desempenho.

Uma outra característica das escolas eficazes está ligada à organização ou a atmosfera da escola, quer dizer, 
quando o ambiente é ordenado, o processo ensino-aprendizagem apresenta um melhor resultado acadêmico.

A escola que possui elementos envolvidos com o compromisso de permanência das camadas populares, no sistema escolar, necessita elaborar um projeto pedagógico global, identificando com clareza os objetivos propostos e partir para a realização deste trabalho coletivo com competência e dedicação. Tomando como referencial a cultura popular, a escola deve ensinar a ler, escrever, calcular, falar, transmitindo conhecimentos básicos do mundo físico e social, sendo útil às camadas populares e deixando de ser instrumento de poder para ser instrumento de anti-poder.

Este tipo de projeto poderá evidenciar a escola democrática, assim idealizada por Guiomar Mello:

"A escola democrática será aquela que conseguir interagir com as condições de vida e com as aspirações das camadas populares... E quem mais depende da escola para a aquisição de conhecimentos $e$ de habilidades intelectuais são os que não dispõe do "currículo oculto" que as condições materiais podem oferecer." (1982:21).

Nas escolas bem sucedidas, o planejamento é configurado como atitude que implica conhecimentos e reflexão sobre a realidade na qual se pretende atuar. Isto significa dar prioridade ao planejamento participativo como processo dialético ação-reflexão-ação. Assim procedendo, a escola contribui para dar sentido bem mais profun- 
do e conseqüente à seleção de conteúdos, dos procedimentos metodológicos e dos instrumentos de avaliação, de modo a assegurar sua perfeita integração e uma interdisciplinaridade, que permita ao aluno obter melhor formação geral e profissional, levando-o a compreender que está em um mundo, onde ele é o sujeito que precisa conhecer os matizes e nuances deste mundo e modificálo. Além disto, Ivani Fazenda afirma que a interdisciplinaridade é uma "atitude capaz de revolucionar os hábitos já estabelecidos" provocando "a superação da dicotomia ensino-pesquisa" promovendo uma educação permanente e incentivando a "formação de pesquisadores e de pesquisas."

Resta ressaltar o suporte da participação dos pais como fator de contribuição na tarefa escolar. Estes, também, possuindo expectativas de sucesso acadêmico para seus filhos, devem estar envolvidos na administração colegiada, participando na tomada de decisões importantes para a escola.

Enfim, como traço mais importante nas condições dos estudos realizados, tanto as escolas eficazes como aquelas que se norteiam pelos princípios ora apontados, são escolas que desenvolvem capacidade para exercer uma autonomia pedagógica e administrativa que, de fato, assume uma cultura de sucesso atendendo à expectativa de aprendizagem dos alunos. 


\subsubsection{Análise do Processo Avaliativo}

O corolário dos princípios enfocados completa-se com a análise do processo avaliativo, que é visto como componente do processo intitulado Educação.

A avaliação deve acompanhar a construção do conhecimento para redirecionar este processo sempre que necessário, a partir da reflexão feita, numa primeira instância, por professores e alunos. Reflexão esta que, tendo como referência o binômio retromencionado, amplia-se, concentricamente, da sala de aula para todas as instâncias da sociedade.

Sob esta perspectiva, a preocupação primeira da avaliação não pode ser a quantidade de conteúdos desenvolvidos, mas, a qualidade da reelaboração e produção de conhecimentos, empreendida por alunos e professores. Esta avaliação deve permear o planejamento das estratégias e a utilização de recursos já consagrados, como ponto de apoio e impulsão para ações criativas que garantam os resultados desejados, constituindo-se em resposta à indagação da professora Jussara Hoffmann:

"Se a avaliação na vida tem gosto de recomeçar, de partir para melhor, de fazer muitas outras tentativas, por que, na escola, se mantém o significado sentencivo, provas de fracasso, periodicidade rígida?" (1994:191).

É evidente que se fala em escola, porém avaliação ocorre na sala de aula, onde os principais personagens 
são o aluno e o professor. Impinge-se ao primeiro a responsabilidade pelo fracasso escolar, tendo em vista que o segundo, geralmente, não atinge a essência do problema da avaliação: as suas causas determinantes, bem como a própria participação dele mesmo (o docente) neste processo. Não atingindo a essência do problema, o professor acaba por utilizar a avaliação como instrumento de pressão, de controle, de ajustamento comportamental do aluno e, o que é pior, como instrumento de discriminação e de seleção social. Por seu intermédio, a escola separa os "aptos" para assumirem seus lugares no sistema dominante e, os "inaptos" para aceitarem o lugar que lhes é destinado, por sua própria responsabilidade em relação à essa "inaptidão". Tudo isto amparado numa legislação escolar que ratifica a ocorrência.

Várias são as causas que contribuem para o professor distorcer o sentido da avaliação. O professor Celso Vasconcellos indica as seguintes razões:

- Por necessidade - o professor apresenta uma proposta de trabalho inapropriada que fatalmente traz problemas sociais cujas causas ele não aborda. ( processo de construção do conhecimento, relação escola-sociedade e outras), preferindo sufocar as consequências, ameaçando os alunos com as notas;

- Por ingenuidade - não tem visão da totalidade da avaliação e suas implicações processuais, ignorando o que é avaliar numa perspectiva emancipatória;

- Por comodidade - mudar implica alterar rotinas, o que dá trabalho e não compensa financeiramente; 
- Por convicção - preparar para vida é propiciar momentos de tensão, já que o cotidiano do indivíduo está permeado por eles. E também, pelo fato de que acredita firmemente que nem todos tem condições de ascenção e a escola precisa identificar os "inaptos";

- Por pressão - o professor é cobrado, pela escola e pelos colegas, no sentido de continuar fazendo a avaliação tradicional e ele acaba por se dobrar à pressão, mesmo já tendo um nivel de consciência.

A ênfase no lugar que o professor ocupa no processo de avaliação não significa que ele é o único responsável pelo direcionamento da avaliação, sob o enfoque que vem sendo imposto pela sociedade capitalista. Todo o aparelhamento escolar contribui para maximizar este direcionamento tão criticado por Young, Giroux e outros pesquisadores que, a nível internacional e nacional, vêmse dedicando ao estudo da problemática educacional.

\section{CONCLUSÃO}

Os estudos e reflexões em torno do assunto, ora abordado, desvelaram alguns aspectos importantes da realidade educacional. A educação escolar pode e deve sofrer mudanças para deixar de ser instrumento de legitimação das diferenças entre as classes sociais. Constatou-se a existência dessa possibilidade pela compreensão de que legitimar diferenças sociais não faz parte da natureza da educação, e cabe à sociedade o compromisso 
de oferecer educação integral a todos os seus membros e em todos os seus níveis. Contudo, pelas próprias dinâmicas da sociedade e da educação, não existe uma educação ideal, universalmente, aceita. O sistema de educação e muito mais o currículo escolar, sistematizado no interior das escolas, refletem o momento histórico da sociedade que os estabeleceu. É possível redirecioná-los, desde que se conheça tanto esta sociedade quanto o seu momento histórico. Ao conhecê-los, desnuda-se o poder e têm-se condições de lutar para que o sistema e o currículo venham a atender os objetivos das classes mais necessitadas.

Em outras palavras, há que haver um equilíbrio entre as perspectivas externa e interna, sob as quais se reflete em torno da problemática educacional. Razão pela qual a perspectiva externa deste trabalho teve o seu ponto de apoio na Nova Sociologia da Educação, e a perspectiva interna embasou-se no trabalho de pesquisadores e educadores brasileiros retromencionados, que têm analisado a complexidade da prática pedagógica, teorizando sobre os problemas reais que acontecem no âmago da escola.

$\mathrm{O}$ avanço consolidou-se na indicação concreta de alguns princípios que, expostos didática e longitudinalmente, não perderam sua perspectiva dinâmica. O próprio Young reconhece que a Nova Sociologia da Educação pouco influiu no cotidiano das escolas, por não apresentar propostas reais e alternativas de mudanças, como as que ora se indicam. No detalhamento de cada princípio fica evidente que eles se acham, intrinsecamente, vinculados uns aos outros. A reflexão sobre os contextos só 
faz sentido se é feito, tendo como referencial o objetivo de agir sobre e nestes contextos, com competência técnica e compromisso político-social (este último expresso pelo engajamento do professor em sua entidade de classe e nos movimentos de emancipação social). Isto enseja o rompimento com uma prática pedagógica estagnada e a construção coletiva de um saber planejado, executado e avaliado, contínua e permanentemente, no cotidiano escolar.

Só assim o aluno se apropiará de um conhecimento fundamental e destituído de acessórios irrelevantes. Poderá analisar a temporalidade de suas relações sociais, políticas, culturais, econômicas e, até mesmo, éticas. Saberá que a produção da riqueza nacional é resultante do trabalho de milhões de brasileiros e não apenas fruto de um planejamento governamental; que sua ação sobre o espaço natural poderá aperfeiçoá-lo ou destruí-lo; que o conhecimento é produção do homem e lhe confere poder e responsabilidade em relação à vontade e à liberdade dos que não o detém; que sua história é datada, socializada e pode ser transformada por ele mesmo. Entenderá que o domínio da linguagem caracteriza a singularidade do seu existir, possibilitando-lhe estruturar e expressar os próprios pensamentos e comunicar-se com seus semelhantes.

Enfim, perceberá que o mundo é uma totalidade conceituada, seriada, classificada, comparada, ou seja, sistematizada pelo ser humano, para ser compreendida e transformada, numa infinita busca de perfeição e felicidade máximas. 


\section{REFERÊNCIAS BIBLIOGRÁFICAS}

ANDRE, Marli - A pesquisa no cotidiano escolar. In: FAZENDA, Ivani (org.). Metodologia da pesquisa educacional. São Paulo : Cortez Editora, 1994, p. 37-45.

APPLE, Michal - Ideologia e currículo. São Paulo : Brasiliense, 1979.

BARMAN, Louise M. Novas prioridades de currículo. Porto Alegre : Globo, 1976.

BELLERATE, Bruno M. Teoria da didática. São Paulo : Cortez,1993.

CANDAU, Vera Maria (Org.). Rumo a uma nova didática. Petrópolis, Rio de Janeiro : Vozes, 1988.

FAZENDA, Ivani Catarina Arantes. Integração $e$ interdisciplinaridade no ensino brasileiro : efetividade ou ideologia? São Paulo : Loyola, 1979.

FORQUIN, Jean Claude. Escola e cultura : as bases sociais e epistemológicas do conhecimento escolar, trad. Guacira Lopes Louro. Porto Alegre : Artes Médicas, 1993.

GIROUX, Henry A. Curriculum \& instruction. Califórnia, USA : McCutchan Publishing Corporation, 1981. 
HOFFMANN, Jussara M. L. Avaliação mediadora : uma prática em construção da pré-escola à universidade. Porto Alegre : Educação e Realidade, 1994.

, Avaliação: Mito \& desafio. Uma perspectiva construtivista. Porto Alegre : Educação e Realidade, 1993.

MARTINS, Pura L. O. Didática teórica \& didática prá- tica. São Paulo : Edições Loyola, 1991.

MELLO, Guiomar N. de. Magistério de $1^{\circ}$ grau: Da competência técnica ao compromisso político. São Paulo : Cortez, 1982.

. Escolas eficazes : um tema revisitado. Brasília: SEPLAN/PR, 1993 (Trabalho Apresentado no Seminário "Gestão Escolar-Desafios e Tendências").

. Educação escolar e classes populares. In: ALVES, Nilda (Coord.). Educação \& supervisão : o trabalho coletivo na escola. São Paulo : Cortez, 1988, p.11-22.

MOREIRA Antônio F. B. Currículos e programas no Brasil. Campinas : Papirus, 1990.

Escola, currículo e a construção do conhecimento. São Paulo : USP, 1991 (Trabalho apresentado na $9^{\text {a }}$ Conferência da Educação no Brasil). 
OLIVEIRA, Ma Rita N.S. Didática : ruptura, compromisso e pesquisa. Campinas : 1993.

VASCONCELOS, Celso dos S. Avaliação dialétical libertadora do progresso de avaliação escolar. São Paulo : Cadernos Pedagógicos do Libertad, 1993.

YOUNG, Michael F.D. Uma abordagem do estudo dos programas enquanto fenômenos do conhecimento socialmente organizado. In: GRÁCIO, Sérgio e STOER, Stephen. Sociologia da educação II : a construção social das práticas educativas. Lisboa : Livros Horizonte, 1982. 